\title{
Leaching of Gold and Silver from Crushed Au-Ag Wastes
}

\author{
Jana Ficeriová*,a ${ }^{*}$ Peter Baláža ${ }^{\mathrm{a}}$ Erika Dutkováa and Eberhard Gock ${ }^{\mathrm{b}}$ \\ ${ }^{a}$ Institute of Geotechnics of the SAS, Watsonova 45, 04353 Košice, Slovakia \\ ${ }^{b}$ Institute of Mineral and Waste Processing and Dumping Technology, Technical University Clausthal, Walther-Nernst \\ Strasse 9, 38678 Clausthal-Zellerfeld, Germany
}

\begin{abstract}
Au-Ag noble metal wastes represent a wide range of waste types and forms with various ballast elements and components. The thiourea process of gold and silver extraction from ores, concentrates or secondary raw materials consists of gold and silver leaching into the thiourea solution and the consequent precipitation of these metals from the solution. Due to the non-toxic character of thiourea it is the perspective alternative to the up to now most frequently used cyanide method. The thiourea leaching of gold and silver from electronic waste, goldsmith's waste and ceramic waste using crushing as the pretreatment step was investigated. For electronic waste, it was possible to achieve $97 \%$ gold and $94 \%$ silver recovery within 120 minutes of thiourea leaching. Up to $98 \%$ of gold and $96 \%$ of silver were recovered from goldsmith's waste after 60 minutes of leaching. In the case of ceramic waste, we achieved up to $98 \%$ gold and $97 \%$ silver extraction efficiency after only 45 minutes of leaching. In comparison with the classical cyanide leaching, thiourea leaching acts faster and without a harmful environmental impact.
\end{abstract}

Keywords: Waste, Gold, Silver, Crushing, Leaching.

\section{INTRODUCTION}

Electronic waste comprises electric waste and includes an extremely complex mixture of electric, electronic and other components. Sources are production waste from the electric and electronic industry as well as defect or technically obsolete devices for which there is a legal obligation for disposal on trade and municipalities [1].

The main components of electronic waste are approximately: $45 \%$ ferrous metals, $10 \%$ non-ferrous metals (mainly $\mathrm{Cu}$ and $\mathrm{Al}$ ), $22 \%$ plastics and $9 \%$ glass.

In contrast, the average fraction of electronic components is only $3 \%$. Most utilization firms call the circuit board including the attached elements and the frame electronic components. From this viewpoint, the fraction of electronic waste is usually between 20 and $30 \%[2,3]$.

There are considerable differences between the composition of the individual groups of electronic waste and even within one group. For assistance, washing machines and refrigerators consist almost completely of ferrous metals and contain a very small fraction of electronics. Computers and entertainment electronics, however, have a high fraction of electronics. The percentage of noble metals is much higher in computers than in the other categories of electronic waste. The following examples give some general indications: low value (<100 ppm Au) TV-boards, monitor boards, (cordless) phones, calculators, shredded bulk material after Al-Feseparation; medium value (100 to $400 \mathrm{ppm} \mathrm{Au}$ ) PC-boards, laptop- and handheld-computers, some mobile phones; high value (> $400 \mathrm{ppm} \mathrm{Au}$ ) Circuit boards from main-frames, some mobile phones, multi-layer ceramic capacitors [4].

*Address correspondence to this author at the Institute of Geotechnics of the SAS, Watsonova 45, 04353 Košice, Slovakia; Fax: + 421-55-7922604; E-mail: ficeri@saske.sk
The secondary resources of gold are generated by craftsmanship and industrial processing of gold and alloys thereof (goldsmith's fractions and fillings, abrasives tailings, clad clock waste and used melting crucibles); by amortization of products (ceramic waste, old jewelry and fractions thereof, dental alloys, graded electrical and electronic waste, nongraded electronic waste); by collecting (medals, coins, bank alloys, sacral and museum treasures), gold lost in the seas and oceans, buried in the graves and in the decommissioned deposits [5].

Gold and silver is impractical connected on the component of Au-Ag wastes included with abundance of accompanying elements and cannot come in contact with leaching solutions. Leaching of $\mathrm{Au}-\mathrm{Ag}$ wastes without pretreatment remitted in low Au and Ag extraction [6].

Physical pretreatment by crushing have been applied to Au-Ag wastes with the aim of changing the part sizes of the gold and silver-bearing wastes, thus facilitating the subsequent leaching in order to increase the recovery of noble metals $[7,8]$. Crushing induces changes size of component parts of $\mathrm{Au}-\mathrm{Ag}$ wastes. It increases the fraction of components and improves their contact with leaching reagents.

Modern hydrometallurgy of gold and silver is based on the application of cyanide leaching. The cyanide process is a highly toxic technology. The thiourea process of gold and silver extraction from wastes or concentrates consisting of gold and silver leaching into the thiourea solution, and consequent precipitation of these metals from the solution is, with regard to the very low toxicity of thiourea, the perspective alternative hitherto the most used cyanide method. Thiourea leaching has more rapid kinetics for gold and silver solubilization than classical cyanide leaching [9-13].

The aim of this work was to examine the possibility of recovering gold and silver from electronic, goldsmith's and ceramic wastes using thiourea leaching. Crushing was ap- 
Table 1. Chemical Composition of Au-Ag Wastes Under Study

\begin{tabular}{|c|c|c|c|c|c|c|c|c|c|c|c|}
\hline \multirow{2}{*}{ Waste } & \multicolumn{11}{|c|}{ Components (\%) } \\
\hline & Au & Ag & $\mathbf{C u}$ & $\mathbf{P b}$ & $\mathbf{Z n}$ & $\mathbf{F e}$ & $\mathbf{B r}$ & Sn & $\mathbf{N i}$ & $\mathbf{S b}$ & Mn \\
\hline Goldsmith's (Slovakia) & 0.8 & 0.45 & 0.53 & 0.041 & 0.012 & 0.008 & - & - & 0.005 & 0.004 & 0.0003 \\
\hline
\end{tabular}

plied in order to determine its effect on the recovery of gold and silver.

\section{EXPERIMENTAL}

\subsection{Materials}

The electronic waste (PC-boards, Germany), goldsmith's waste (abrasive papers, Slovakia) and ceramic waste (pink porcelain, Czech Republic) were selected as materials for testing the thiourea leaching of gold and silver. The chemical composition of the studied wastes is given in Table $\mathbf{1}$.

\subsection{Physicochemical Characterization}

The X-ray fluorescence spectroscopy (XRF) was done using a Philips PW 1404 (X-tal LiF 200) spectrometer equipped with a source operating at $40 \mathrm{kV}$ and $30 \mathrm{~mA}$. Data

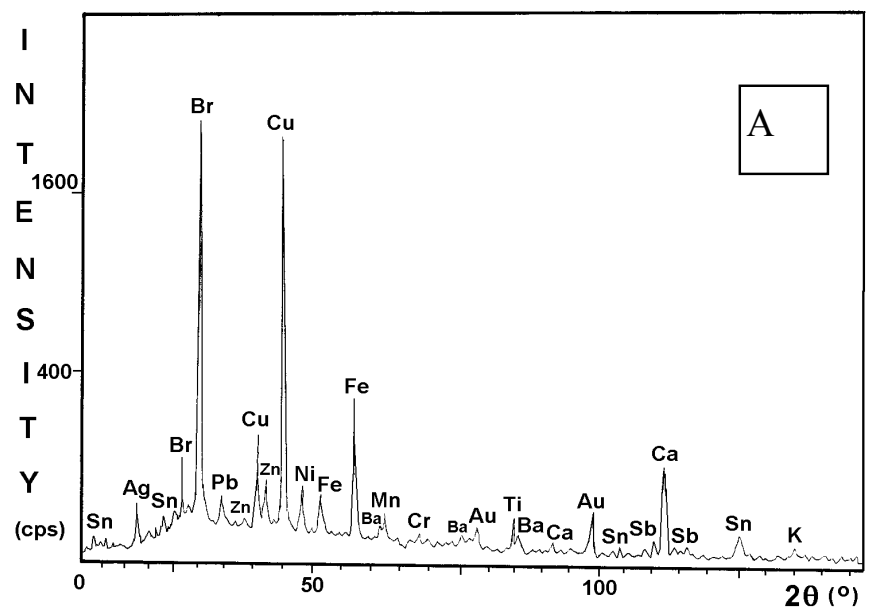

were collected every second and the detector was moved at a rate of $0.1^{\circ} \mathrm{min}^{-1}$.

\subsection{Crushing of Au-Ag Wastes}

Rotoplex-shredder crusher A20/12 Ro and Omniplexhammer crusher 40/20 Ha (both Alpine, Germany) were used for treatment of electronic, ceramic and goldsmith's wastes. After crushing, the material was $8 \times 8 \mathrm{~mm}$ in size in case of goldsmith's waste and $-800 \mu \mathrm{m}$ in case of electronic/ceramic waste. Before leaching the waste has been sieved.

\subsection{Thiourea Leaching of Au-Ag Wastes}

The leaching was investigated in a $500 \mathrm{~mL}$ glass reactor into which $400 \mathrm{~mL}$ of leaching solution having $10 \mathrm{gL}^{-1}$ $\mathrm{CS}\left(\mathrm{NH}_{2}\right)_{2}, 5 \mathrm{gL}^{-1} \mathrm{Fe}_{2}\left(\mathrm{SO}_{4}\right)_{3} .9 \mathrm{H}_{2} \mathrm{O}, 10 \mathrm{gL}^{-1} \mathrm{H}_{2} \mathrm{SO}_{4}$ and $50 \mathrm{~g}$

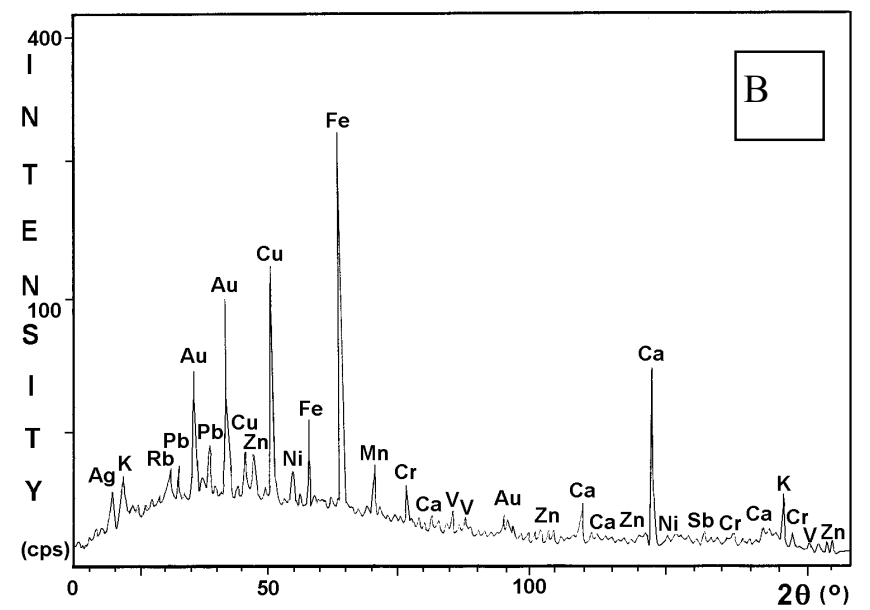

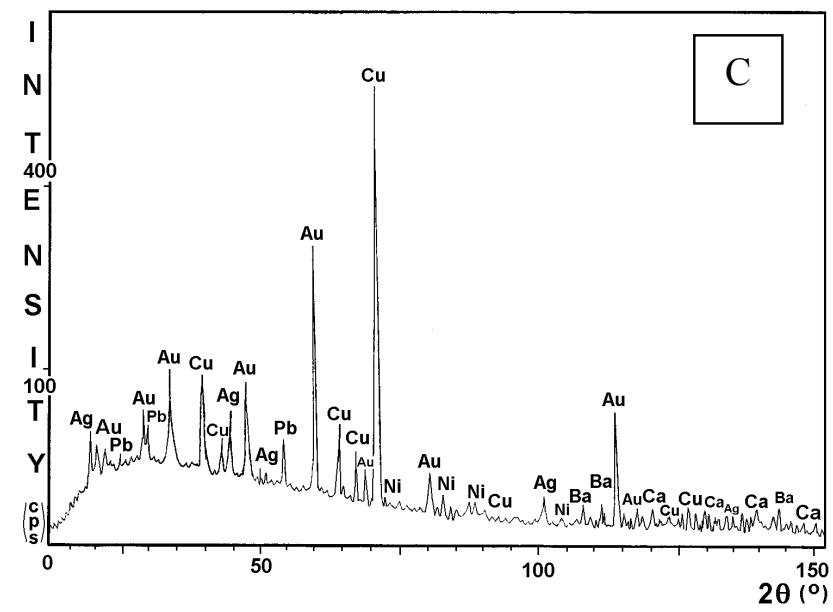

Fig. (1). X-ray fluorescence spectrum of electronic waste (A), goldsmith's waste (B) and ceramic waste (C). 
of crushed electronic, goldsmith's and ceramic wastes were added. The leaching was performed at $\mathrm{pH} 1$ for up to 120 min at $293 \mathrm{~K}$ using a stirring rate of $8.33 \mathrm{~s}^{-1}$. Aliquots $(5 \mathrm{~mL})$ of the solution were withdrawn at appropriate time intervals for determination of the content of dissolved gold and silver by AAS method.

The leaching kinetics of gold and silver were best fitted by the kinetic equation:

$$
-\ln \left(1-\varepsilon_{x}\right)=k_{X} t_{L}
$$

where $\varepsilon_{\mathrm{x}}$ is recovery of gold/silver into the leach solution, $\mathrm{k}_{\mathrm{X}}$ is the rate constant $\left(\mathrm{s}^{-1}\right)$ and $\mathrm{t}_{\mathrm{L}}$ is the leaching time $(\mathrm{s})$.

Thiourea, $\mathrm{CS}\left(\mathrm{NH}_{2}\right)_{2}$ forms a stable soluble complex with gold and silver ions. Bruckard [14] suggested the equations for gold and silver dissolution in the presence of $\mathrm{Fe}^{3+}$ ions as:

$$
\begin{aligned}
& \mathrm{Au}+2 \mathrm{CS}\left(\mathrm{NH}_{2}\right)_{2}+\mathrm{Fe}^{3+} \rightarrow \mathrm{Au}\left[\mathrm{CS}\left(\mathrm{NH}_{2}\right)_{2}\right]_{2}^{+}+\mathrm{Fe}^{2+} \\
& \mathrm{Ag}+3 \mathrm{CS}\left(\mathrm{NH}_{2}\right)_{2}+\mathrm{Fe}^{3+} \rightarrow \mathrm{Ag}\left[\mathrm{CS}\left(\mathrm{NH}_{2}\right)_{2}\right]_{3}^{+}+\mathrm{Fe}^{2+}
\end{aligned}
$$

\section{RESULTS AND DISCUSSION}

\subsection{Thiourea Leaching of Gold and Silver from Crushed Au-Ag Wastes}

The X-ray fluorescence spectral records of the Au-Ag wastes under study, are shown in Fig. (1). The results confirm the presence of gold/silver and following metallic and non-metallic elements.

The dependence of gold and silver recovery on the leaching time from electronic waste is shown in Fig. (2). 120 min leaching of "as-received" sample with thiourea yielded only a $76 \% \mathrm{Au}$ and $71 \% \mathrm{Ag}$ leachate (Fig. 3). The treatment using crushing makes it possible to achieve a more than 90 $\%$ recovery of gold and silver in the leachate even after 6090 minutes. Here, the recovery of accompanying metals was $68 \% \mathrm{Cu}, 45 \% \mathrm{Fe}, 43 \% \mathrm{~Pb}$ and $28 \% \mathrm{Zn}$. The results for crushed waste show increased recoveries of noble metals.

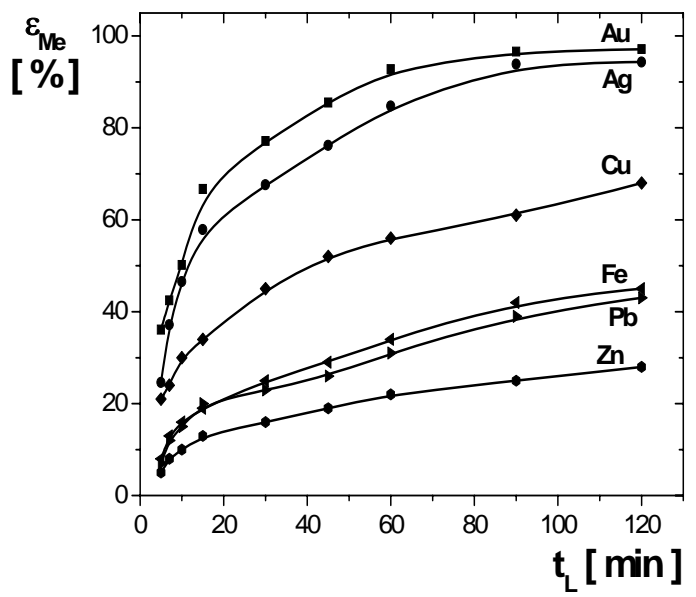

Fig. (2). Recovery of $\mathrm{Au}, \mathrm{Ag}, \mathrm{Cu}, \mathrm{Fe}, \mathrm{Pb}$ and $\mathrm{Zn}, \varepsilon_{\mathrm{Me}}$ vs. leaching time, $t_{L}$ for electronic waste (Germany) pretreated by Omniplexhammer crusher, 40/20 Ha (Alpine, Germany).

Fig. (4) shows the effect of leaching time on gold and silver recovery for crushed goldsmith's waste. In the "as- received" sample $87 \%$ of gold and $83 \%$ of silver was recovered after $120 \mathrm{~min}$ of leaching in thiourea (Fig. 5). The results for the treated waste indicated that the comminution of the Au-Ag waste brought about an acceleration of the leaching process. In this case, it was possible to achieve 99 $\%$ gold recovery and about $96 \%$ silver recovery after less than 60 min of leaching. Here, the recovery of accompanying metals was $87 \%$ for $\mathrm{Cu}, 55 \%$ for $\mathrm{Fe}$ and $28 \%$ for $\mathrm{Zn}$.

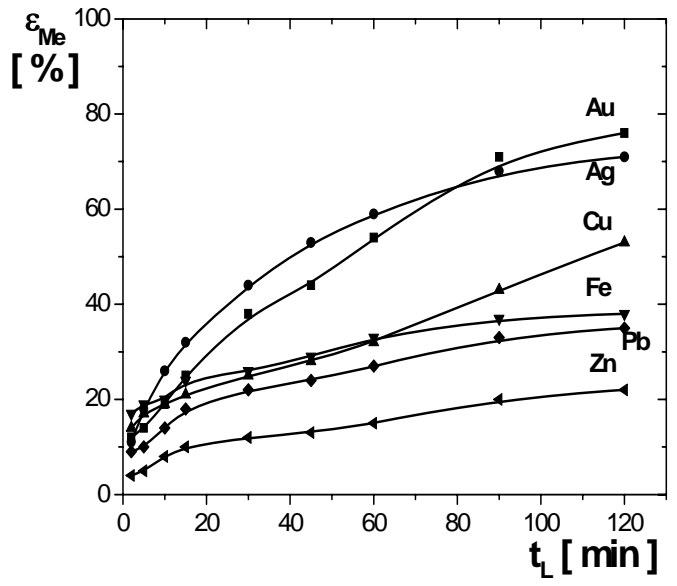

Fig. (3). Recovery of $\mathrm{Au}, \mathrm{Ag}, \mathrm{Cu}, \mathrm{Fe}, \mathrm{Pb}$ and $\mathrm{Zn}, \varepsilon_{\mathrm{Me}} v s$. leaching time, $t_{\mathrm{L}}$ for "as- received" sample of electronic waste (Germany).

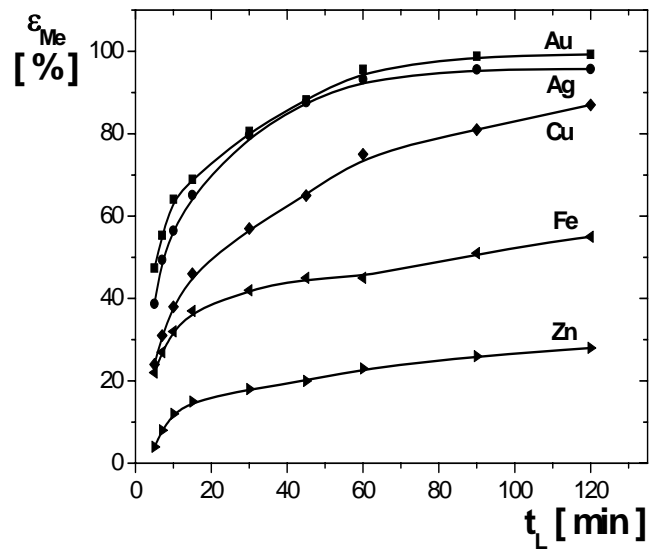

Fig. (4). Recovery of $\mathrm{Au}, \mathrm{Ag}, \mathrm{Cu}, \mathrm{Fe}$ and $\mathrm{Zn}, \varepsilon_{\mathrm{Me}} v s$. leaching time, $\mathrm{t}_{\mathrm{L}}$ for goldsmith's waste (Slovakia) pretreated by Rotoplex-shredder crusher, A20/12 Ro (Alpine, Germany).

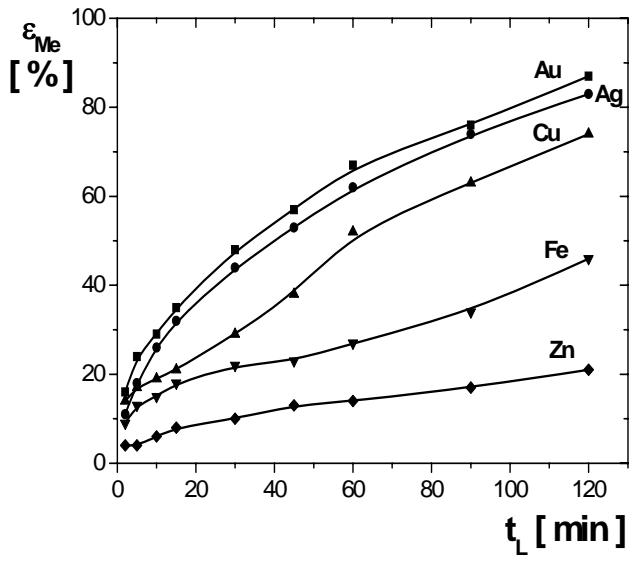

Fig. (5). Recovery of $\mathrm{Au}, \mathrm{Ag}, \mathrm{Cu}, \mathrm{Fe}$ and $\mathrm{Zn}, \varepsilon_{\mathrm{Me}} v s$. leaching time, $t_{L}$ for "as-received" sample of goldsmith's waste (Slovakia). 
The dependence of gold and silver recovery as well as the recovery of accompanying metals $(\mathrm{Cu}$ and $\mathrm{Pb})$ for the crushed ceramic waste is given in Fig. (6). It is possible to achieve a $98 \%$ recovery of gold and $97 \%$ recovery of silver into the leachate even after 45 minutes. After $120 \mathrm{~min}$ of leaching, $71 \%$ of $\mathrm{Cu}$ and $18 \%$ of $\mathrm{Pb}$ was recovered. A recovery of $90 \% \mathrm{Au}$ and $\mathrm{Ag}$ was achieved after 120 min of leaching of the "as-received" sample (Fig. 7).

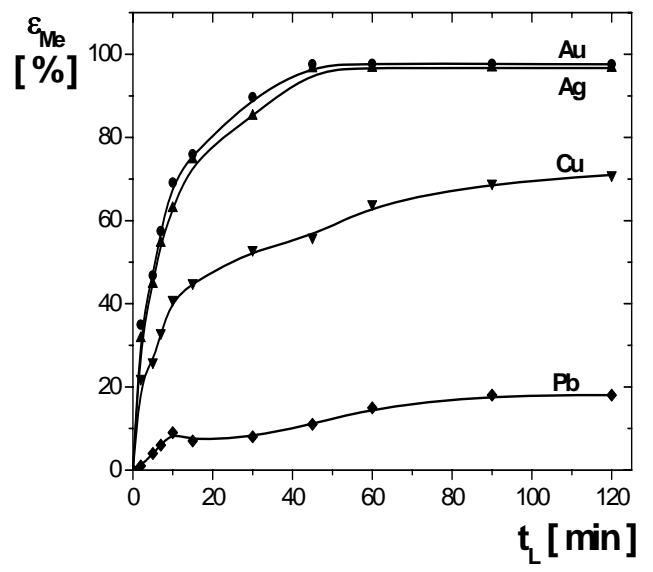

Fig. (6). Recovery of $\mathrm{Au}, \mathrm{Ag}, \mathrm{Cu}$ and $\mathrm{Pb}, \varepsilon_{\mathrm{Me}} v$ s. leaching time, $\mathrm{t}_{\mathrm{L}}$ for ceramic waste (Czech Republic) pretreated by Omniplexhammer crusher, 40/20 Ha (Alpine, Germany).

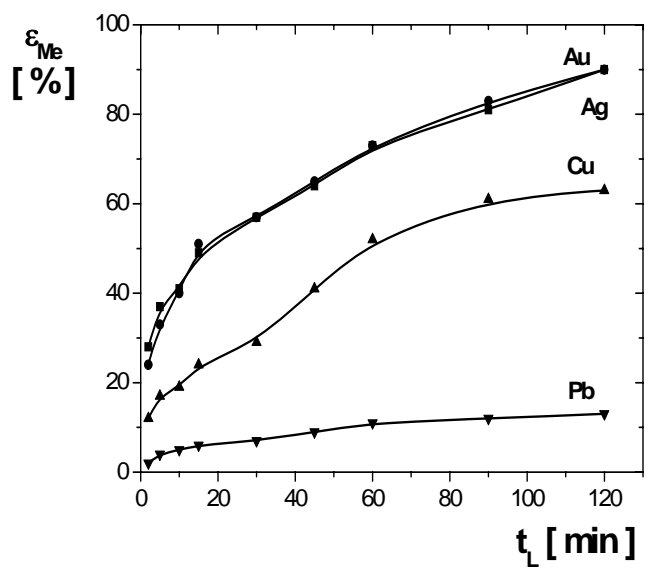

Fig. (7). Recovery of $\mathrm{Au}, \mathrm{Ag}, \mathrm{Cu}$ and $\mathrm{Pb}, \varepsilon_{\mathrm{Me}} v$ s. leaching time, $\mathrm{t}_{\mathrm{L}}$ for "as-received" sample of ceramic waste (Czech Republic).

The application of crushing proved to be an effective method of pretreatment of the Au-Ag wastes before extraction of gold and silver into thiourea leaching liquors.

\section{CONCLUSIONS}

Crushing of Au-Ag electronic, goldsmith's and ceramic wastes from Germany (Clausthal-Zellerfeld), Slovakia
(Košice) and Czech Republic (Praha) in a shredder crusher and hammer crusher influences the changes part sizes of the gold and silver-bearing wastes and this leads to an accelerated thiourea leaching. It increases the fraction of components and improves their contact with leaching reagents. Thiourea leaching is more suitable for rapid extraction of gold and silver from the given types of $\mathrm{Au}-\mathrm{Ag}$ wastes than other alternatives. In this way, it is possible to achieve more then $90 \%$ recovery of gold and silver.

The process of thiourea leaching is non-toxic and moreover brings kinetic advantage over classical cyanide leaching.

\section{ACKNOWLEDGEMENTS}

This work was supported by the Slovak Grant Agency for Science (Grant No. 2/0035/08).

\section{REFERENCES}

[1] J. Shibata and A. Okuda, "Recycling technology of precious metals", Resour. Mater., 48, pp. 23-31, 2003.

[2] S. Thimao and J. Shu, "The recovery of gold and silver from electronic waste", J. Metals, 6, pp. 53-57, 2004.

[3] Ch. Hagelüken, "Recycling of electronic scrap at Umicore's integrated metals smelter and refinery", Erzmetall, 59, pp. 152-161, 2006.

[4] B. Langner, "Recycling of electronic scrap", Metall, 48, pp. 880885, 1994.

[5] J.E. Hoffmann, "Recovering precious metals from electronic scrap and goldsmith's waste", J. Metals, 4, pp. 43-48, 2002.

[6] J. Brusselaers and J. Kegels, "Eco efficient optimization of preprocessing and recycling of srap", Erzmetall 39, pp.122-131, 2004.

[7] D. Tange, "Properties of ceramic and electronic wastes", Resour. Mater., 26, pp. 31-35, 2002.

[8] J. Ficeriová, P. Baláž, and E. Gock, "A processing method of the goldsmith's and electronic Au-Ag containing wastes", Acta Montan. Slovaca, 10, pp. 307-310, 2005.

[9] F. Habashi, A Textbook of Hydrometallurgy: Metallurgie Extractive Quebec, Canada, 1993.

[10] P. Baláž, J. Ficeriová, V. Šepelák and R. Kammel, "Thiourea leaching of silver from mechanically activated tetrahedrite", $\mathrm{Hy}$ drometallurgy, 43, pp. 367-377, 1996.

[11] P. Baláž, J. Ficeriová, E. Boldižárová, M. Háber, S. Jeleň and R. Kammel, Thiosulphate leaching of gold from a mechanochemically pretreated complex sulfide concentrate, "Developments in Mineral Processing, 13", in Proc. XXI. International Mineral Processing. Congr., Ed. Paolo Massacci, Elsevier, Amsterdam, Rome, pp. A674 - A6-81, 2000.

[12] P. Baláž, J. Ficeriová, and C.L. Villachica, "Silver leaching from a mechanochemically pretreated complex sulfide concentrate", $\mathrm{Hy}$ drometallurgy, 70, pp. 113-119, 2003.

[13] J. Ficeriová, P. Baláž, and E. Boldižárová, "Influence of mechanochemical pretreatment on leaching of silver in cyanide and noncyanide medium”, J. Mater. Sci., 39, pp. 5339-5341, 2004.

[14] W.J. Bruckard, G.J. Sparrow and J.T. Woodcock, "Gold and silver extraction from Hellyer lead-zinc flotation middlings using pressure oxidation and thiourea leaching", Hydrometallurgy, 33, pp. 17-41, 1993. 